\title{
Variations in the Composition of Egg-yolk Pigment
}

\author{
By F. H. GRIMBLEBY AND D. J. G. BLACK \\ University of Reading
}

(Received ro November 195I)

Gillam \& Heilbron (1935) in a study of the effects of feeding maize and grass on the composition of yolk pigment have shown that xanthophyll is the principal pigment of egg yolk, although cryptoxanthin and $\beta$-carotene are also present, the former sometimes in amounts that contribute appreciably to the total vitamin A activity of the yolk. In view of this, the extent of the variations in the cryptoxanthin and $\beta$-carotene of the yolk is of considerable importance, particularly the variations that may be experienced under the conditions normally adopted for poultry breeding. In the management of breeding stock the hens are almost invariably allowed free range over good pasture, the grass supplying a considerable, and often the greater, part of the hens' requirements for vitamin $A$.

In a previous paper (Grimbleby \& Black, 1950) an experiment was described in which the variation in pigment and vitamin $A$ contents of individual eggs was examined, the eggs being obtained from four birds taken from a breeding flock of Rhode Island Red hens fed on a pigment-free diet but allowed free range over good pasture. No vitamin A supplement was given. The yolk pigments from individual eggs were fractionated, xanthophyll, cryptoxanthin and $\beta$-carotene being separately determined. According to Kuhn, Winterstein \& Lederer (193I) the so-called yolk 'xanthophyll' is a mixture of lutein and zeaxanthin, but the separation of the xanthophyll fraction into these components was not attempted. The vitamin A content of the yolk was also determined and the significance of the variations in total pigment and vitamin A contents of egg yolk was discussed. The present paper deals with the variations in composition of the yolk pigment found in the same experiment.

\section{EXPERIMENTAL}

The experimental procedure adopted for the extraction and separation of the yolk pigments has already been described (Grimbleby \& Black, 1950), but it should be further stated that the identification of the pigments was established by mixed chromatograms, pure zeaxanthin and cryptoxanthin required for this purpose being obtained from Physalis alkakengi by the method of Kuhn \& Grundmann (1933) and the $\beta$-carotene from carrots by the method of Strain (1934). As the separation of lutein and zeaxanthin was not effected by adsorption on magnesium hydroxide under our conditions, pure zeaxanthin was used to identify the position of the so-called xanthophyll fraction.

\section{RESULTS}

The results are shown diagrammatically in Fig. I and summarized in Table $\mathbf{I}$.

They show that the dihydroxycarotenes having no vitamin A activity, lutein and zeaxanthin, usually referred to as 'xanthophyll', are present in considerable amounts 
compared with the active pigments cryptoxanthin and $\beta$-carotene. The quantities found were in close agreement with those found by Gillam \& Heilbron (r935) in bulk samples of yolk. The results show further that, although cryptoxanthin was almost invariably a constituent of yolk pigment, $\beta$-carotene was frequently absent; in the first eggs laid in spring it was, in fact, unusual for $\beta$-carotene to be present. The pigments were found in the eggs of the four birds in the average proportions shown in

Table I. Xanthophyll, cryptoxanthin and $\beta$-carotene contents of individual eggs from four Rhode Island Red hens

\begin{tabular}{|c|c|c|c|c|c|c|c|c|c|c|c|}
\hline \multirow{2}{*}{$\begin{array}{c}\text { Hen } \\
\text { no. }\end{array}$} & \multicolumn{3}{|c|}{$\begin{array}{c}\text { Xanthophyll } \\
\text { (mg/egg) }\end{array}$} & \multicolumn{3}{|c|}{$\begin{array}{c}\text { Cryptoxanthin } \\
\text { (mg/egg) }\end{array}$} & \multicolumn{3}{|c|}{$\begin{array}{c}\beta \text {-carotene } \\
\text { (mg/egg) }\end{array}$} & \multirow{2}{*}{$\begin{array}{l}\text { Av. wt. } \\
\text { of yolk } \\
\text { (g) }\end{array}$} & \multirow{2}{*}{$\begin{array}{c}\text { No. of } \\
\text { determinations }\end{array}$} \\
\hline & Max. & Min. & Av. & ax. & Min. & & & Min. & 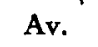 & & \\
\hline $\begin{array}{l}43 \\
46\end{array}$ & $\begin{array}{l}1 \cdot 17 \\
1 \cdot 60\end{array}$ & $\begin{array}{l}0.36 \\
0.31\end{array}$ & $\begin{array}{l}0.68 \\
0.74\end{array}$ & $\begin{array}{l}0.042 \\
0.047\end{array}$ & $\begin{array}{l}\text { None } \\
0.010\end{array}$ & $\begin{array}{l}0.019 \\
0.023\end{array}$ & $\begin{array}{l}0.006 \\
0.007\end{array}$ & $\begin{array}{l}\text { None } \\
\text { None }\end{array}$ & & $\begin{array}{l}19 \cdot 6 \\
19 \cdot 2\end{array}$ & $\begin{array}{l}42 \\
38\end{array}$ \\
\hline $\begin{array}{l}107 \\
162\end{array}$ & $\begin{array}{l}1 \cdot 18 \\
2 \cdot 36\end{array}$ & $\begin{array}{l}0.33 \\
0.29\end{array}$ & $\begin{array}{l}0.52 \\
1.27\end{array}$ & $\begin{array}{l}0.044 \\
0.071\end{array}$ & $\begin{array}{l}0.008 \\
0.013\end{array}$ & $\begin{array}{l}0.015 \\
0.047\end{array}$ & $\begin{array}{l}0.005 \\
\text { Trace }\end{array}$ & $\begin{array}{l}\text { None } \\
\text { None }\end{array}$ & $\begin{array}{l}0.002 \\
\text { Trace }\end{array}$ & $\begin{array}{l}18.4 \\
20.7\end{array}$ & $\begin{array}{l}39 \\
21\end{array}$ \\
\hline
\end{tabular}

Table 2. Ratio xanthophyll:cryptoxanthin: $\beta$-carotene in yolk pigment

(Average values)

$\begin{array}{rccc}\text { Hen no. } & \text { Xanthophyll } & \text { Cryptoxanthin } & \beta \text {-carotene } \\ 43 & 1000 & 28 & 3 \\ 46 & 1000 & 31 & 5 \\ 107 & 1000 & 29 & 4 \\ 162 & 1000 & 37 & \text { Trace }\end{array}$

Table 3. Relation between the contents of xanthophyll and cryptoxanthin of individual eggs

$\begin{array}{cccc}\text { Hen no. } & \begin{array}{c}\text { No. of } \\ \text { determinations }\end{array} & \begin{array}{c}\text { Correlation } \\ \text { coefficient }\end{array} & \begin{array}{c}\text { Significance } \\ \text { Highly significant }\end{array} \\ 43 & 43 & 0.908 & \text { Highly significant } \\ 46 & 38 & 0.946 & \text { Highly significant } \\ 107 & 39 & 0.845 & \text { Highly significant }\end{array}$

Table 2. The cryptoxanthin content of the eggs followed the xanthophyll content very closely, there being a highly significant correlation between the two (Table 3 ). Hen no. I62 stopped laying after only five eggs had been laid in early March and ceased production for 26 days before again coming into lay, with the result that the pigments in the eggs from this bird did not reach the low fluctuating level reached in those of the other three birds, which had maintained a continuous production of eggs over the whole experimental period.

\section{DISCUSSION}

These results raise certain questions about the utilization of $\beta$-carotene and of cryptoxanthin by the hen and about the source of the yolk cryptoxanthin.

Kline, Schultze \& Hart (1932), Record, Bethke \& Wilder (1937) and others have shown that carotene and vitamin $A$ are utilized with equal efficiency by the fowl, but Frey \& Wilgus (1949) reported that, although vitamin $A$ was superior to 


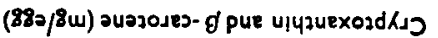

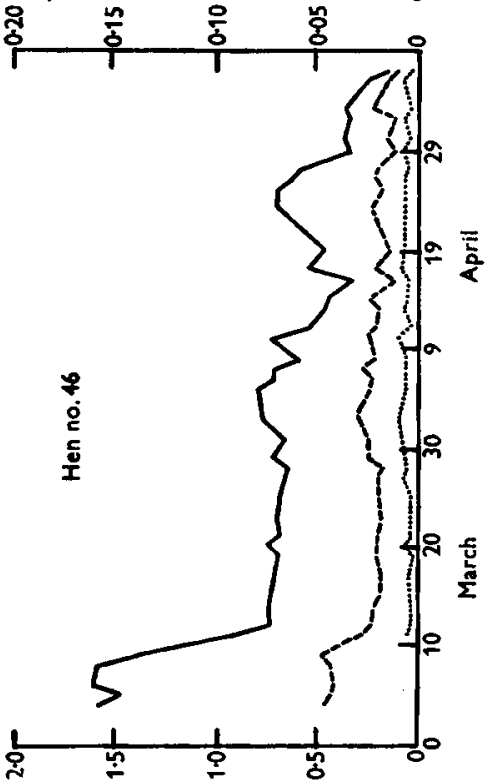

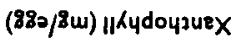

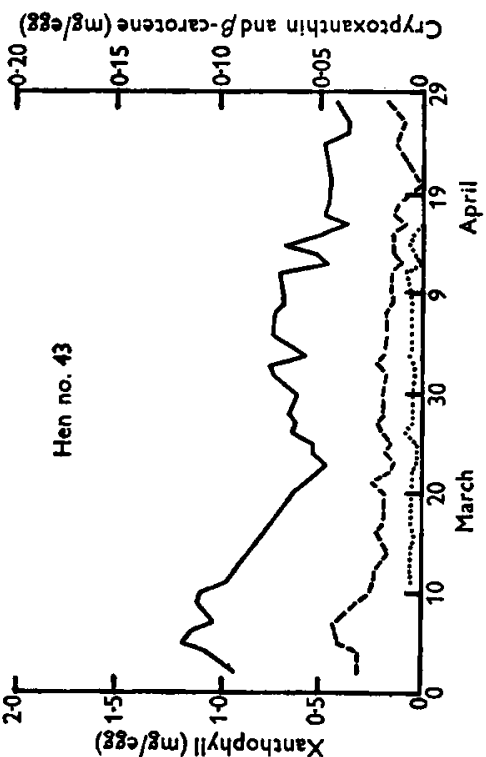

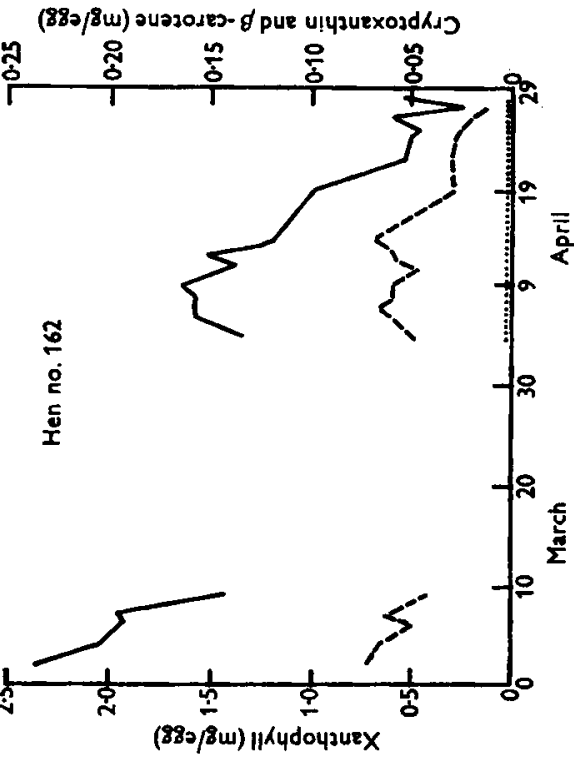

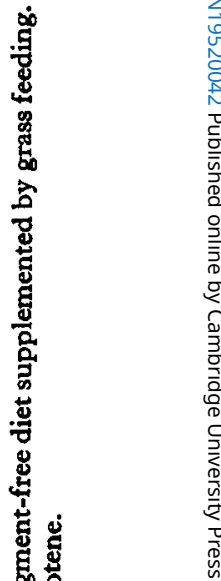

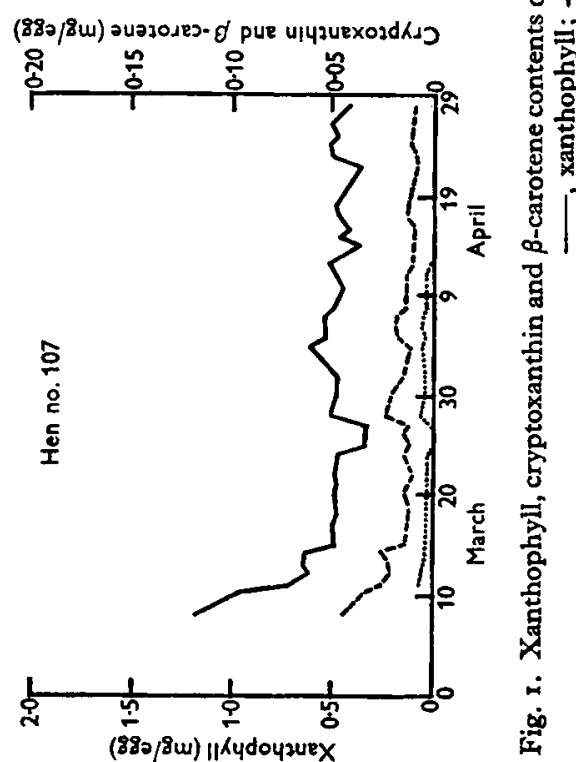


carotene in building liver reserves of vitamin $A$, carotene from alfalfa was superior to vitamin $\mathrm{A}$ for the transfer of vitamin $\mathrm{A}$ and carotene to the egg. In the present experiment the vitamin A requirements of the birds were met entirely by the carotenoid pigments derived from grass, and a highly significant correlation between the total pigment and vitamin A content of individual eggs was, in fact, found (Grimbleby $\&$ Black, 1950). It must be assumed, therefore, that $\beta$-carotene was assimilated in amounts comparable with those of the inactive pigments, and the very small quantities of $\beta$-carotene in the eggs indicate that little of the $\beta$-carotene absorbed escaped conversion to vitamin $A$.

The absence of $\beta$-carotene from the first few eggs laid after a rest from egg-laying suggests that the pigments transferred to these eggs had been held in store by the hens for a sufficient length of time to permit the conversion of all assimilated $\beta$-carotene to vitamin $A$. When this store was somewhat depleted and pigments were transferred more directly from feed to egg, there was a tendency for some $\beta$-carotene to escape this conversion, but the amount was always small.

The quantities of cryptoxanthin found were sufficient to contribute appreciably to the total vitamin A activity of the yolk. The eggs from all birds contained on the average $0.023 \mathrm{mg}$ cryptoxanthin, equivalent to 19 i.u. vitamin $\mathrm{A}$ (assuming that $0.0012 \mathrm{mg}$ cryptoxanthin $\equiv \mathrm{I}$ i.u. vitamin $\mathrm{A}$ ). The average vitamin $\mathrm{A}$ content of the same eggs was 182 i.u. so that the cryptoxanthin present, if utilizable by the fowl, would increase the total vitamin $A$ activity of each egg by about 10\%. The presence of such quantities of cryptoxanthin in the eggs, compared with the very small amounts of $\beta$-carotene, suggests that cryptoxanthin was not converted to vitamin $A$ as readily as $\beta$-carotene, but the quantities of the various pigments ingested by the hens were not determined, so that no definite conclusion can be reached on this matter.

One point of considerable interest arising from these results concerns the source of the yolk cryptoxanthin. This pigment was present in all but one of the eggs examined; further, a highly significant correlation was found between the contents of cryptoxanthin and xanthophyll of individual eggs. The possibility that the presence of the cryptoxanthin was due to storage by the hens during a previous period of intake is discounted by the close correlation found between the cryptoxanthin and xanthophyll contents, as some, at least, of the latter must have been obtained from grass recently eaten. Further, Titus, Fritz \& Kauffman (1938) have shown that the amount of stored pigment transferred to eggs falls progressively to insignificant amounts after about eleven eggs have been laid, whereas we found fluctuating amounts in eggs up to the fortieth egg laid. It would appear therefore that the two pigments were derived from the same source, yet, so far as we are aware, cryptoxanthin has not been reported to be a constituent of grass, and our examination of grass has not revealed its presence. It would appear therefore that the hen is able to alter other carotenoid pigments to cryptoxanthin, although from the data available it is not possible to say which carotenoid pigment is involved. The conversion of zeaxanthin or lutein to cryptoxanthin would mean that the hen does, in fact, utilize vitamin A-inactive pigments for the synthesis of vitamin A-active ones, as has been suggested by Virgin \& Klussmann (1932). 


\section{SUMMARY}

I. Successive eggs from four birds in a breeding flock of Rhode Island Red hens, maintained on a grain ration free from pigment and vitamin $A$ but allowed free range over good pasture, were analysed for their xanthophyll, cryptoxanthin and $\beta$-carotene contents.

2. The pigment in egg yolk was mainly a mixture of lutein and zeaxanthin, usually referred to as xanthophyll. Cryptoxanthin and $\beta$-carotene were also present in small amounts.

3. A significant correlation was found between the cryptoxanthin and xanthophyll contents of eggs from hens receiving grass in the diet.

4. The significance of the presence of cryptoxanthin and the variation in the contents of the various pigments are discussed.

\section{REFERENCES}

Frey, P. R. \& Wilgus, H. S. (1949). F. Nutrit. 39, 517.

Gillam, A. E. \& Heilbron, I. M. (1935). Biochem. F. 29, 1064.

Grimbleby, F. H. \& Black, D. J. G. (1950). Brit. F. Nutrit. 4, 323.

Kline, O. L., Schultze, M. O. \& Hart, E. B. (1932). F. biol. Chem. 97, 83.

Kuhn, R. \& Grundmann, C. (1933). Ber. dtsch. chem. Ges. 66, 1746.

Kuhn, R., Winterstein, A. \& Lederer, E. (193I). Hoppe-Seyl. Z. 197, 141.

Record, P. R., Bethke, R. M. \& Wilder, O. H. M. (1937). Poult. Sci. 16, 25.

Strain, H. H. (1934). F. biol. Chem. ro5, 523 .

Titus, H. W., Fritz, J. C. \& Kauffman, W. R. (1938). Poult. Sci. 17, 38.

Virgin, E. \& Klussmann, E. (1932). Hoppe-Seyl. Z. 213, 16. 